\title{
ERYTHEMA MARGINATUM
}

\author{
BY \\ JOYCE B. BURKE \\ From the Children's Hospital, Sheffield, and The Hospital for Sick Children, Great Ormond Street, London
}

(RECEIVED FOR PUBLICATION MARCH 16, 1955)

\begin{abstract}
-The signs may be difficult for the physician to interpret and thus cures are slow and mistrust in the power of the doctor persists. - - Hippocrates (translated from the original Greek by John Chadwick and W. N. Mann).
\end{abstract}

The association of erythematous skin rashes with rheumatic fever was recognized by physicians of the last half century. Perry (1937) reviewed the literature on the subject of erythema marginatum and described 13 cases seen in Bristol over a period of five years. His description of the rash was very similar to that of erythema annulare given by Lehndorff and Leiner in 1922. He wrote that the lesions start as a solid erythema which may be slightly raised. The erythema extends outwards while the skin in the centre returns to normal, hence the name erythema marginatum. Adjacent lesions coalesce, forming larger rings. Keil (1938) studied 523 cases of rheumatic fever admitted to the Mount Sinai Hospital, and in 53 of these an erythematous rash occurred. In 14 this took a papular form, and in 39 a rash with a marginate edge was present. Keil mentioned two variants of this, erythema marginatum and erythema annulare. In the first of these the edge is raised, and in the second the lesions are entirely macular, but the author admitted that it is often difficult to make a clear distinction between the two, as lesions of both types may be seen together and they have a similar distribution, course, duration and diagnostic significance. Jones (1944) stated that in his experience erythema marginatum is by far the most significant cutaneous manifestation of rheumatic fever, and he named it as one of the major criteria for diagnosis of this disease. He did not differentiate erythema marginatum and erythema annulare.

Lehndorff and Leiner considered that erythema annulare was only seen in children with rheumatic carditis. Wallgren (1935) studied 148 children with rheumatic fever, and of these 88 were 'very mild cases of endocarditis which healed relatively rapidly and only seven had erythema annulare, whereas it was seen in eight of 27 children with very severe rheumatic carditis. In his opinion there is no doubt that erythema annulare occurs more frequently in severe than in mild rheumatic fever. Endocarditis was demonstrated clinically at some time in 17 of 18 children with erythema annulare seen in four years (1931-34). Five of the children died, a fatal outcome was expected in a further three, in three the prognosis was 'doubtful', while in seven it was considered to be good. In contrast, Perry regarded erythema marginatum as of favourable prognostic significance, because five of his 13 patients made a complete recovery, five had permanent cardiac damage, in one the disease was still active and two had died. Keil (1938) came to the conclusion that involvement of the heart 'practically always' accompanies the cutaneous manifestation of rheumatic fever.

Is erythema marginatum a specific rheumatic manifestation? Perry thought it to be so and Lehndorff and Leiner and Wallgren held similar views with reference to the macular form, erythema annulare. These writers noted, however, that the rash may continue to appear when all other signs of rheumatic activity have subsided. Keil was more cautious and said that an eruption may only be regarded as rheumatic in origin in the presence of other manifestations of acute rheumatism. $\mathrm{He}$ mentioned drug and serum eruptions in the differential diagnosis, but stated later that in childhood the rash may be regarded as almost certain evidence of acute rheumatism.

The purpose of this paper is to present 19 cases of erythema marginatum, 14 of which were associated with rheumatic fever. Six of the children were included in the joint Anglo-American investigation sponsored by the Medical Research Council, into the use of cortisone, A.C.T.H. and salicylates in rheumatic fever. The 19 children were seen in the Children's Hospital, Sheffield, or The Hospital for Sick Children, Great Ormond Street, London. In this paper no distinction is made between erythema marginatum and erythema annulare and only the term 'erythema marginatum' is used. 


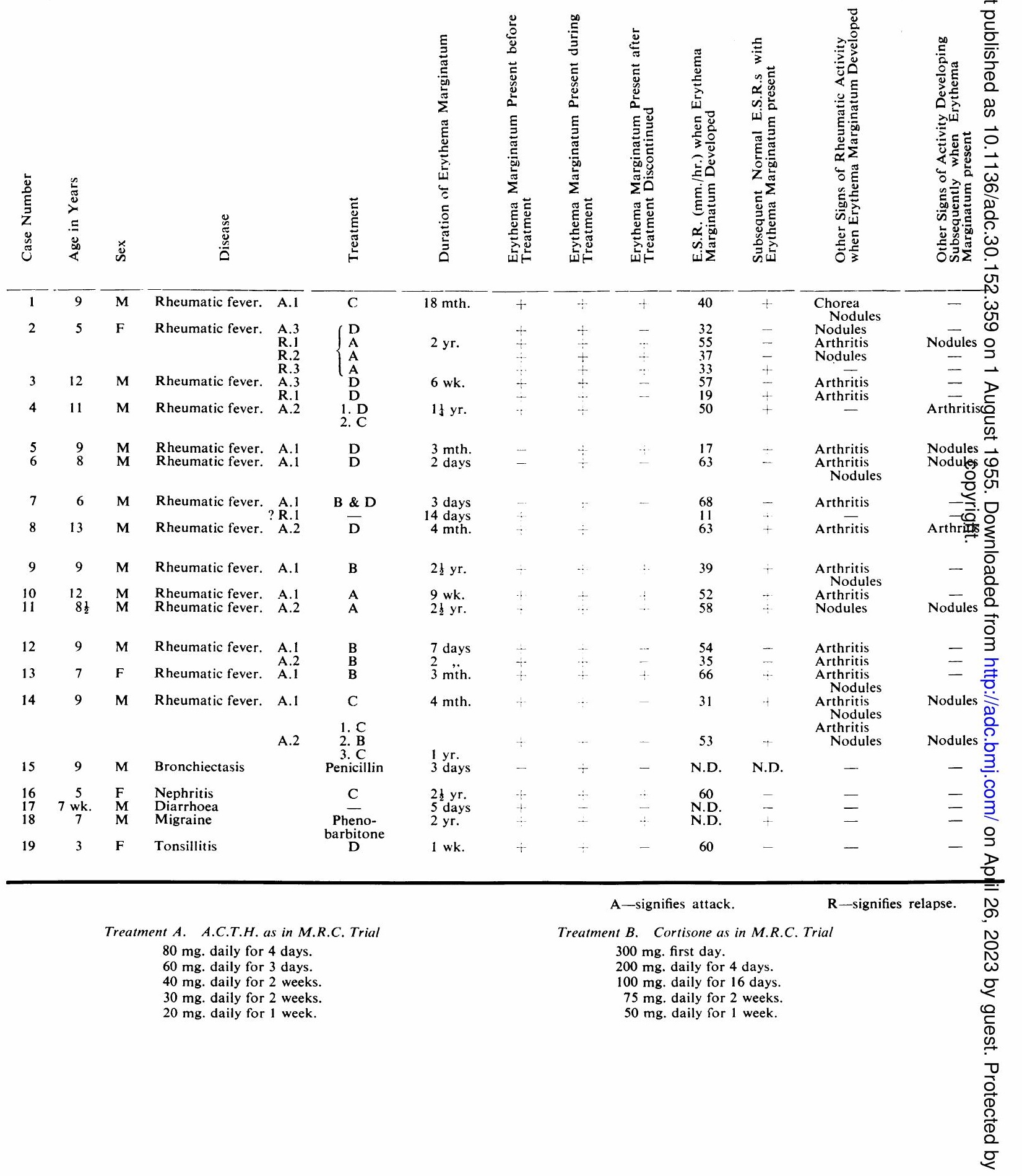


Erythema Marginatum Associated with Rheumatic Fever

Details of the 14 cases are summarized in Table 1. It will be seen that they did not all come under observation in their first attack. When further rheumatic manifestations appeared before the patient had returned to full activity, the term relapse is used.

Study of Table 1 shows that the rash may appear at any time during or after an attack of rheumatic fever. In 11 cases (Nos. 1, 2, 3, 4, 8, 9, 10, 11, 12, 13 and 14) it was present at the onset, and in three cases it made its first appearance later in the course of the disease, in Case 5 after four months, in Case 6 after two weeks and in Case 7 after five days.

The distribution of the rash was as described by the writers previously mentioned, in that there was a predilection for the trunk and proximal parts of the limbs, the face being spared. Irritation and desquamation did not occur. The lesions were eranescent, in many instances passing through the cycle of changes described above in the course of a few hours, fresh lesions then appearing to repeat the cycle. The total duration was extremely variable from two days only in Case 6 to intermittent appearances for over two years in Cases 9 and 11 .

The presence of erythema marginatum could not be correlated with the height of the sedimentation rate, for, while it is true that the sedimentation rate was raised when the rash first appeared in all 14 cases, in five cases (Nos. 1, 5, 9, 10 and 11) fresh lesions continued to appear when a normal value had been reached and all other signs of rheumatic activity had subsided. A profuse crop of new lesions was associated with recurrence of activity in four cases (Nos. 2, 3, 12 and 14), but there were exceptions to this, as shown by Cases 7 and 9 . Case 7 developed fever and erythema marginatum six months after his first attack of rheumatic fever when the sedimentation rate was $11 \mathrm{~mm}$. in one hour. On admission to hospital, Case 9 had fever, polyarthritis, acute carditis, nodules and erythema marginatum. He was treated with cortisone for six weeks. There was a rapid response and within 14 days all symptoms had subsided, although fleeting erythema marginatum continued. After a fortnight without treatment he developed a temperature of $103^{2} \mathrm{~F}$. and complained of a sore throat. A profuse crop of fresh lesions appeared. No 3 Haemolytic streptococci were isolated from his throat and the sedimentation rate was $10 \mathrm{~mm}$. in one hour. Neither arthritis nor carditis recurred and no fresh nodules were seen. The temperature settled within three days and the rash faded, but continued to appear at intervals for two and a half years. There has been no other evidence of rheumatic activity and his heart is now normal clinically.

Erythema marginatum was uninfluenced by salicylates, cortisone or A.C.T.H. in the doses given, although other manifestations of rheumatic activity such as fever, arthritis and elevation of the sedimentation rate usually subsided. Fresh lesions appeared throughout the period of treatment in every case except No. 12. This child's rash disappeared within seven days of starting treatment in his first attack and within two days in his second. In Cases 4, 13 and 14 there was an immediate rise of temperature and sedimentation rate with recurrence of arthritis when attempts were made to discontinue treatment, but erythema marginatum continued in spite of treatment.

Acute carditis was present in all 14 cases. It preceded the appearance of the rash in three cases (Nos. 5, 6 and 7). Nine children (Cases 1, 2, 4, 6, $7,8,11,13$ and 14) had severe cardiac involvement and it is almost certain that cardiac damage is permanent in three (Nos. 2, 11 and 14). At the time of follow-up examination six children have apparently normal hearts (Nos. 1, 3, 5, 9, 10 and 12), in three cases the disease is still active (Nos. 4, 8 and 13), and, although cardiac murmurs can still be heard in Cases 6 and 7, it is less than six months since signs of rheumatic activity disappeared.

The duration of erythema marginatum and the extent of cardiac damage bear no apparent relationship to each other, as the following cases show. Case 6 had a loud aortic diastolic murmur and a mitral systolic murmur when first seen. Erythema marginatum appeared 14 days later lasting for two days only. The cardiac signs have remained unchanged for 16 months, except for some diminution in intensity of the mitral murmur. Treatment was discontinued five months ago. Case 1 presented with chorea, nodules, erythema marginatum and acute carditis, mitral and aortic systolic and diastolic murmurs being heard. All evidence of rheumatic activity subsided within three months, but erythema marginatum continued for 18 months. He has now been followed up for three years and his heart has been normal clinically for the past year. Case 9 had an apical systolic murmur for 18 months which then disappeared. He still has fleeting erythema marginatum two and a half years after his attack of rheumatic fever.

Nodules were seen in eight of the 14 cases (Nos. $1,2,5,6,9,11,13$ and 14) and fresh nodules appeared while the patient was having treatment in five (Nos. 2, 5, 6, 11 and 14). Erythema marginatum and nodules sometimes occurred together, but this was not always so as is shown by the following 
examples. Case 2 was given salicylates in high dosage in her third attack of rheumatic fever and no fresh nodules or erythema marginatum appeared. In her first relapse she was admitted to the M.R.C. investigation. Numerous fresh nodules continued to appear for eight weeks in spite of treatment with A.C.T.H. and erythema marginatum was seen intermittently for seven months. Case 5 developed two nodules during the first fortnight of treatment with salicylates. Erythema marginatum occurred after four months of treatment by which time the nodules had disappeared. In Case 6 fresh nodules continued to appear for the first month after starting treatment and erythema marginatum was seen for two days only during this time.

Case 11 was treated with A.C.T.H. and fresh nodules continued to appear for five months and erythema marginatum for two and a half years. During the first three months erythema marginatum was profuse and on three occasions fresh lesions were associated with a crop of new nodules. Case 14 was treated with salicylates in his first attack. Fever and arthritis subsided rapidly, but he developed a mitral diastolic murmur and fresh nodules appeared for one month. Erythema marginatum continued for four months. Salicylates were given for one month in his second attack, but treatment was then changed to cortisone because fresh nodules and erythema marginatum continued to appear. The sedimentation rate had fallen from $53 \mathrm{~mm}$. in one hour to $25 \mathrm{~mm}$. in one hour. Cortisone was given for seven weeks and during this time no fresh nodules were seen, but the rash persisted and he developed a pericardial friction rub and an aortic diastolic murmur. As soon as cortisone was stopped a profuse crop of nodules appeared and the sedimentation rate rose from $3 \mathrm{~mm}$. in one hour to $30 \mathrm{~mm}$. in one hour. Salicylates were then given for 11 months. No fresh nodules appeared and the sedimentation rate fell to normal in two weeks. Erythema marginatum continued for nine months. Thus it will be seen that erythema marginatum and nodules both appear to be uninfluenced by treatment.

Bacteriological studies are complicated by the fact that patients often receive sulphonamides or penicillin at the onset of any febrile illness before admission to hospital, and once treatment was started all these children were given prophylactic sulphadiazine or penicillin, and those in the M.R.C. trial had four injections of a long-acting penicillin preparation in addition. It was found that throat swabs had been taken on 18 occasions when erythema marginatum was actually present and $\beta$ Haemolytic streptococci were isolated in seven cases. The organisms were not grcuped or typed.

Estimations of the serum antistreptolysin $\mathrm{O}$ titre (A.S.O.) were only done routinely on the six cases in the M.R.C. series. In all the children the figure was maximal at the onset of the attack of rheumatic fever and gradually fell to normal. It rose again in Case 12 when he was admitted in his second attack. Erythema marginatum was present at the beginning of the attack in all six when the A.S.O. titre was high, but subsequent appearance of the rash and its total duration could not be related to the level of the A.S.O. titre (Table 2).

\section{Erythema Marginatum Unassociated with Acute Rheumatism}

Five cases of erythema marginatum are described below, in four of which there was no question of the presence of acute rheumatism. In the fifth the diagnosis of rheumatic fever was possible, but considered to be unlikely.

Case 15. A 9-year-old boy with bronchiectasis developed erythema marginatum on the trunk and legs on two occasions following penicillin injections.

Case 16. A girl, 5 years of age, was admitted to hospital with extensive erythema marginatum and acute

TABLE 2

ANTI-STREPTOLYSIN O TITRE IN RELATION TO THE OCCURRENCE OF ERYTHEMA MARGINATUM

\begin{tabular}{|c|c|c|c|c|c|c|c|c|c|c|c|c|c|c|c|c|c|c|}
\hline \multirow{3}{*}{$\begin{array}{l}\text { Case } \\
\text { No. }\end{array}$} & \multirow{3}{*}{$\begin{array}{c}\text { Duration of } \\
\text { Erythema } \\
\text { Marginatum }\end{array}$} & \multicolumn{17}{|c|}{ Anti-streptolysin O Titre (units/ml.) } \\
\hline & & \multicolumn{17}{|c|}{ Time in Months } \\
\hline & & Onset & 1 & 2 & 3 & 4 & 5 & 6 & 7 & 8 & 9 & 10 & 11 & 12 & 18 & 24 & 30 & 36 \\
\hline 1 & $18 \mathrm{mth}$. & 125 & N.D. & 50 & N.D. & 50 & N.D. & 50 & 50 & 50 & 50 & 50 & 50 & $<50$ & 50 & 50 & 50 & 50 \\
\hline 2 & 2 yr. & 200 & 833 & N.D. & 50 & 50 & 50 & 50 & 50 & 50 & 50 & $<50$ & 50 & 50 & 50 & 50 & & \\
\hline 9 & $2 \frac{1}{2}$ yr. & 200 & 200 & 125 & 50 & 50 & $<50$ & $<50$ & $<50$ & $<50$ & N.D. & $<50$ & 50 & 50 & 50 & 50 & & \\
\hline 10 & 9 wk. & 333 & 200 & 125 & 50 & 50 & 50 & 50 & 50 & 50 & 50 & 50 & 50 & 50 & 50 & 50 & 50 & 50 \\
\hline 11 & $2 \frac{1}{2} \mathrm{yr}$ & 500 & 500 & 333 & 333 & 500 & 500 & 200 & 500 & 200 & 200 & 200 & 125 & 200 & 50 & 50 & 50 & . \\
\hline 12 & $\begin{array}{ll}\text { A.1 } & 7 \text { days } \\
\text { A.2 } & 2 \text { days }\end{array}$ & 200 & 125 & 125 & 125 & 50 & 50 & 50 & 125 & $<50$ & $<50$ & $<50$ & $<50$ & $<50$ & $<50$ & $<50$ & 2,500 & \\
\hline
\end{tabular}


nephritis. The rash had been present intermittently for eight months before admission. She was discharged after three months, by which time the urine was normal, but the rash continued to appear. Four months later haematuria recurred and she was admitted to hospital for a further eight months. $\beta$ Haemolytic streptococci were isolated from the throat. Red cells and casts disappeared from the urine, but albuminuria remained and she developed slight oedema of the face and limbs. Erythema marginatum persisted in spite of a course of systemic penicillin and antihistamine drugs in increasing dosage (mepyramine maleate up to $150 \mathrm{mg}$. six-hourly). Sodium salicylate was next tried, 15 grains being given six-hourly. The rash disappeared immediately and was not seen for three weeks. It appeared when the drug was discontinued and was uninfluenced by a second course of salicylates. The child was last seen five months after discharge from hospital and the rash was still occurring, albuminuria was present, and numerous granular and cellular casts were seen in the urinary deposit with occasional red cells. A trace of oedema of the legs and face persisted. She died four months later.

Case 17. A boy of 7 weeks, under observation because of failure to gain weight and occasional loose stools, had erythema marginatum of the legs and trunk for five days. He was afebrile and was not receiving drugs at the time.

Case 18. A boy of 7 years was referred to hospital with a diagnosis of ringworm. He was found to have typical erythema marginatum on the trunk and limbs. His mother said the rash had been present intermittently for two years. He had occasional migraine, but apart from this was very fit. There was no history of tonsillitis or acute rheumatism. Clinical examination was negative apart from the rash. No $\beta$ Haemolytic streptococci were isolated from the throat, and the sedimentation rate was $6 \mathrm{~mm}$. in one hour. He had been given aspirin and phenobarbitone for the headaches, but the rash was first seen at least a year before the drugs were given and it continues to appear although he had had no drugs for six months.

Case 19. A 3-year-old girl was admitted to hospital because she had developed profuse erythema marginatum after an attack of tonsillitis. On examination she was found to be febrile and a moderately loud (Grade II) systolic murmur was heard down the left border of the sternum. The sedimentation rate was $60 \mathrm{~mm}$. in one hour, and $\beta$ Haemolytic streptococci were not isolated from the throat. There were no other symptoms or signs of rheumatic fever. A diagnosis of probable rheumatic carditis was made and she received salicylates in high dosage for a month. Treatment was then discontinued because of doubt about the diagnosis. The temperature settled within a few days of starting salicylates and the erythema marginatum faded rapidly. The sedimentation rate fell to $26 \mathrm{~mm}$. in one hour and remained between 20 and $40 \mathrm{~mm}$. in one hour for two years, although she was in excellent health and leading a normal life. The heart murmur has not changed and it would almost certainly be regarded as functional were it not for the previous history, but in view of this, its significance remains in doubt.

The electrocardiogram and screening of the heart show no abnormality. Eighteen months after her first admission the child had another attack of tonsillitis from which she made a rapid recovery. Erythema marginatum was not seen.

\section{Discussion}

There can be little doubt that erythema marginatum and rheumatic fever are often related in some way, but this study throws no light on the nature of the relationship. The association of the rash with other manifestations of so-called rheumatic activity, as judged by elevation of the sedimentation rate, fever, arthritis, nodules and acute carditis, is quite inconstant and in the present state of our knowledge it would seem illogical to treat erythema marginatum with salicylates, cortisone or A.C.T.H. and unjustifiable to restrict a patient in any way on account of the rash, in the absence of other signs of rheumatic activity.

The observations confirm the findings of Lehndorff and Leiner (1922), Wallgren (1935), Perry (1937) and Keil (1938) with regard to the high incidence of carditis in cases of erythema marginatum. In the present series the rash was of no immediate prognostic significance, but a much longer follow-up will be required in order to determine whether erythema marginatum presages permanent cardiac damage, for if carditis has been present at any time the inexorable process of scarring with final permanent valvular damage may have been set in motion in spite of the fact that for some years the heart may appear normal on clinical examination.

The occurrence of undoubted erythema marginatum in conditions other than rheumatic fever indicates that it is a non-specific phenomenon, and in this respect it resembles erythema nodosum. The association with acute nephritis is of interest, as both these diseases are thought to follow infection with Group A $\beta$ Haemolytic streptococci, but erythema marginatum and acute nephritis are rarely seen together.

\section{Summary}

Fourteen cases of erythema marginatum associated with rheumatic fever are presented. The rash varied in duration from two days to two and a half years and was uninfluenced by treatment with salicylates, cortisone or A.C.T.H. It is shown that erythema marginatum may persist when all other signs of rheumatic activity have subsided, and long after the sedimentation rate has returned to a normal value. 
Carditis was present in all 14 cases. At the time of the last follow-up examination six children had apparently normal hearts, three had sustained permanent cardiac damage and in five the observation period was too short for final cardiac assessment.

Four cases of erythema marginatum unassociated with rheumatic fever are described, and a fifth in which the relationship is doubtful. Erythema marginatum is therefore a non-specific phenomenon.
My thanks are due to Professor R. S. Illingworth for encouragement and advice in the preparation of this paper, to Dr. B. Schlesinger, Dr. G. H. Newns and Professor A. Moncrieff for permission to publish their cases, and to Dr. B. M. Buck for help in reviewing the literature.

References

Jones, T. D. (1944). J. Amer. med. Ass., 126, 481.

Keil, H. (1938). Ann. intern. Med., 11, 2223.

Lehndorff. H. and Leiner, C. (1922). Z. Kinderheilk., 32, 46.

Perry, C. B. (1937). Archives of Disease in Childhood, 12, 233.

Wallgren, A. (1935). Acta paediat., Uppsala, 17, 447 